\title{
Characteristics of small medium contractor entrepreneurs: a study of Indonesia
}

\author{
Harijanto Setiawan ${ }^{*}$, Ferianto Raharjo, and Koesmargono \\ Atma Jaya Yogyakarta University, Civil Engineering Department, 55281 Yogyakarta, Indonesia
}

\begin{abstract}
The success of entrepreneurship as an important driving force for business success cannot be separated from the role of entrepreneurs. Therefore study about entrepreneurs in contractor business in Indonesia is considered important to be carried out. This study is aimed at identifying the characteristics of contractor entrepreneurs who owned small medium contractors in Indonesia. The study is conducted based on eight characteristics of entrepreneurs that have been identified from the literatures: risk taking, innovativeness, need for achievement, internal locus of control, self-confident, tolerance of ambiguity, need for autonomy and proactiveness. The study adopts qualitative research approach in which the data are collected from interviews with the owner of small medium contractors in Indonesia. Then the data are categorized by a coding process using NVivo 10 software and analysed using thematic analysis with inductive approach. The study found several specific characteristics of Indonesian small medium contractor entrepreneurs that are related to the eight characteristics of entrepreneurs but under the circumtances of contractor business. After all characteristics were examined further, they are mainly linked to projects, clients and business. This finding is in accordance with the nature of contractors as project based companies.
\end{abstract}

Keywords: Entrepreneurship, Contractors, SMEs, Indonesia

\section{Introduction}

The construction industry has been considered as an industry that drives a country's social and economic establishment $[1,2,3]$. This role is increasingly important in many rapidly developing countries such as Indonesia.

Several types of companies such as contractor, sub-contractor, consultant, and supplier are involved in construction Industry. Among all type of companies, contractors running their activities in many unique ways. Contractors are project-based firm (PBFs) that run their business based on projects that are unique and designed based on client's demands.

In running their business, contractors must deal with a risky situation, required to be innovative and face high competition [4,5]. This business situation also happens in

\footnotetext{
*Corresponding author: haris@mail.uajy.ac.id
} 
Indonesia, therefore appropriate business strategy needs to be developed in order to achieve success in business.

Over the last few decades, entrepreneurship became very popular, phenomenon and widely discussed among people around the world [6, 7]. Entrepreneurship has been considered as a driving force for business success in many business areas [8]. Considering the reliability of entrepreneurship to support business success and the need of contractors to implement the right strategy to achieve business success, it was established that entrepreneurship can be adopted by contractors as a right strategy.

However the implementation of entrepreneurship cannot be separated from the role of people called entrepreneurs. Entrepreneurs have been defined as persons who run their own business $[9,10,11,12,13,14,15]$. In order to be success in running their own business, entrepreneurs are required to be innovative, creative and independent $[10,11,13,14,16]$.

Although the role of entrepreneurship to support business success in several fields has been recognized, there is very little study directed towards entrepreneurship as well as entrepreneurs in construction. Therefore this study will focus on bridging this gap in construction management research by exploring the characteristics of entrepreneurs in small medium contractors. The study is carried out in Indonesia, therefore the particular circumstances of the construction industry in Indonesia will characterise this study.

In order to achieve the aim of this study, the specific research objectives have been established as follows: (1) to explore characteristics of entrepreneurs from literatures in a systematic way and (2) to identify the characteristics of small medium contractor entrepreneurs in Indonesia.

\section{Literature Review}

\subsection{Characteristics of Entrepreneurs}

Over the years various characteristics of entrepreneurs have been widely studied. Entrepreneurs are distinguished from owner-managers; because not all owner-managers can be considered as entrepreneurs [17]. In running the business, an owner-managers tend to focus on surviving, while entrepreneurs have a desire to grow in addition to survive. Therefore owner-managers only have survival instinct while entrepreneurs have both survival and growth instinct. Furthermore, the characteristics that are considered as growth instinct are: opportunistic, willingness to take greater risks, innovative, self-confident, proactive and decisive with high energy, able to live with greater uncertainty, selfmotivated, having vision and flair.

Six psychological characteristics of entrepreneurs which are need for achievement, internal locus of control, propensity to take risk, tolerance of ambiguity, self-confidence and innovativeness have been investigated [18]. These six characteristics became frequently cited in the previous similar studies. In addition, autonomy is included because it is found as one of entrepreneur's needs and this need is higher than people in general [19]. Another study used three of these characteristics: need for achievement, risk taking propensity and internal locus of control to link psychological traits of entrepreneur and business performance [20].

Later on the personality characteristics of entrepreneurs such as embracing risk taking, innovativeness, need for achievement, internal locus of control, proactive personality, stress tolerant, and with passion for work have been described in the previous study [21]. These characteristics, together with human capital and environment factors, can support the active performance of the entrepreneur to achieve success.

After reviewing all of these characteristics, it was found that some characteristics have 
similar meanings but are identified by using different terms or words, and some characteristics can be considered as a part of other characteristics, Finally this study considers eight characteristics that distinguish people who have entrepreneurial tendencies from those who do not. The eight characteristics are: risk taking, innovativeness, need for achievement, self-confident, internal locus of control, tolerance of ambiguity, need for autonomy and proactiveness. All of these characteristics are explored further in the following section.

\section{Risk taking}

Risk taking refers to a tendency to take an opportunity which required decision making under uncertain conditions $[18,22]$. In particular it was emphasized that an entrepreneur's risk taking must be distinguished from the behaviour of gambler [22]. The entrepreneur takes a risk under controllable circumstances, therefore the risk taking behaviour of entrepreneurs is considered as calculated risk taking, which involves not only luck but skill as well. It was found higher performance entrepreneurs have a higher propensity to take risk taking action compared to lower level performers [20].

\section{Innovativeness}

Entrepreneur's ability to create innovation has been considered as one of two most important characteristics of entrepreneurs; the second major characteristic is being opportunistic [17]. However, innovation is needed in order to create and to exploit opportunity. Innovativeness is defined as creating and implementing new ideas such as new product, new service, new system or new strategy in order to achieve success of the company [21]. He considered innovativeness is related to self-starting, although they are different. Innovation is an important aspect of self-starting because self-starting is contrary to imitating what has already been done by others.

\section{Need for achievement}

Need for achievement is related to the ambition of individuals to achieve their goal rapidly and perfectly. This ambition motives the individual to defeat all constraints that prevented the goals from being reached [19]. Particularly entrepreneurs are characterized by high need of achievement [22]. It was found that the higher the need of achievement, the higher the entrepreneurs' performance [20]. However the achievement levels of peoples may vary depending on the individual and an entrepreneurs' achievement is usually associated with money [17].

\section{Internal locus of control}

Locus of control is related to an individual's beliefs about who or what controls the actions and achievement of his or her life. This characteristic is distinguished into internal and external locus of control. People with an internal locus of control tend to assume that his or her behaviour is under his or her control; they take responsibility for their actions. Those people with an external locus of control tend to assume that his or her achievement is influenced by external factors and so that individual has little or no control over the outcome of their actions. The entrepreneurs are characterised by having an internal, rather than external, locus of control personality, as do many successful people in a range of professions [18, 19]. Internal locus of control makes people feel competent to achieve their expected goal or goals [22]. Furthermore internal locus of control was found positively 
related to positive entrepreneurial performance [20].

\section{Self-confident}

Uncertainty is the nature of entrepreneur's circumstances; In order to deal with uncertainty, people need to be self-confident [17]. Self-confidence is defined as having the conviction of his or her own ability to be able to achieve expected goals [18, 19]. Furthermore selfconfidence directs people to act properly and effectively in order to be successful [19].

\section{Tolerance of ambiguity}

An ambiguous situation exists when the information about that situation is not fully or sufficiently available [18]. This situation usually occurs in new and complex situations of high risk and high uncertainty. In many cases, an entrepreneur will need to make a deal in an ambiguous situation. Entrepreneurs who characterised by having a high tolerance of ambiguity, consider this situation as a challenge, not a barrier, and will responded positively in such a situation. The limited information available will be fully utilized to achieve optimal results $[18,19]$.

\section{The need for autonomy}

The need for autonomy has a variety of meanings, depending on the context of discussion; however, when it is associated with the personal need for autonomy, the most suitable definition is personal preference to work and to make decisions independently, free from the influence from outsiders [23]. Autonomy leads entrepreneurs to have new and great ideas, therefore business ideas will emerge [24]. Entrepreneurs need independence in order to control the idea, the goal, the business, to be able to work differently, to reach the potential, etc. [17].

\section{Proactiveness.}

Entrepreneurs must be able to seize opportunities quickly and accurately, they should not just wait for 'good luck' [17]. Entrepreneurs should not only be determined and able to seek opportunities but also to anticipate problems that will arise from those opportunities and then to find ways to overcome those problems [22].

\section{Research Method}

Two research methods have been implemented in this study. The study was started by comprehensive review on several literatures to get the characteristics of entrepreneurs in general. Then it was followed by exploratory approach to identify specific characteristics of entrepreneurs in small medium contractors under specific circumstances of Indonesia. This approach was appropriate for this study due to a lack of previous research in entrepreneurs in the area that is particularly related to contractors in Indonesia. The study was started by collected data and then followed by data analysis as explained in the following sections.

\subsection{Data collection}

Data for this study was collected through face to face semi-structured interviews with the owner of small medium contractors in Indonesia. The owners of contractors are considered 
as an appropriate source of data because they are the ultimate decision maker that intensively involved in daily activities of contractors' business. The choice of interviewees constitutes judgemental sampling which determines potential participants by considering their capacity to provide proper and appropriate information related to the investigated issues [25].

Prior to the interview, an interview guide was sent to the participants in order to give them an idea about the interview. The interview guide consists of several questions about the entrepreneur's characteristics that were explored based on several references. During the interviews, communication varied depending on the flow of the conversation therefore the format and sequence of questions did not always expressly follow those outlined on the interview guide. Extra questions were asked to follow up on issues which appeared to be important and relevant to the topic of the interview. The interviewer controlled the interviewee to make sure the focus of discussion was maintained. The interviews lasted between 30 to 60 minutes and each was audio-recorded.

\subsection{Data analysis}

The data collected was analysed using thematic analysis 'bottom up' approach that is data driven. In this approach, themes are identified mainly based on the data [26]. Data driven approach was chosen because of a lack of previous research in the area of entrepreneurs in construction. Then identified themes are directed to the issues that relate to the characteristics of contractor entrepreneurs.

The following processes of data analysis were carried out to identify the characteristics of contractor entrepreneurs.

- Audio-recording of each interview was heard carefully and continuously in order to enable the researcher to be familiar with the data and then initial ideas were extracted from the data.

- Then these audio-recordings were heard carefully but part by part, the sentences, that indicated any characteristics of entrepreneurs, were written-down

- The next step is coding process that was started manually. During manual coding, any sentences, that indicated the same issue, were coded under one node that is still nameless.

- The next coding process was done using NVivo 10 software. In this stage, codes were refined and re-categorized into the appropriate nodes that are considered as important issues related to the characteristics of entrepreneurs.

- Coding process using NVivo 10 software was carried out continuously in three rounds to check whether the issues work in relation to the entire data set or not.

- Finally important issues that explained the characteristics of small medium contractor entrepreneurs were identified then the names and the definitions of the theme is decided based on the sentences that were coded under each node.

\section{Research Findings}

\subsection{Background of small medium contractor entrepreneurs}

The study has interviewed 8 owners of small medium contractors. On average their companies employ full-time staffs ranging from 10 to 20 persons in the main office, whereas if calculated together with the staff and workers in the field projects, they have 
totally about 200 employees. They are not only owners but also are actively involved in running business and project activities.

Based on the interviews, this study found few similar conditions in all interviewees that are considered to be influencing characteristics.

- Starting their business with very limited capital.

None of them get any support from their families or friends in order to start their business therefore they have to fight themselves from scratch without facilities from anyone.

- Starting working as a staff of contractors

Most of them start their career in contractors as a staff. Among them, a few worked for contractors only in a short period, while the rest works in contractors for a long period and got the position of Project Managers.

- Committed to their career step.

All of them always start working in the same industry, such as general contractors or subcontractors for foundation.

- Peoples who are strong in their religions.

All of them believe that all of their achievements cannot be separated from the blessing of God.

\subsection{Entrepreneurial characteristics of small medium contractor entrepreneurs}

The data analysis found seven out of eight characteristics of entrepreneurs have been implemented by small medium contractor entrepreneurs. The only factor that is not implemented is the need of autonomy. Autonomy is not considered as an important issue for contractor entrepreneurs because as the owner, they have had the freedom to run the business in their own way. The characteristics specifically attached to small medium contractor entrepreneurs are presented in Table 1. Each characteristic is clarified by short explanation and examples that raised from interviews.

In addition to the characteristics presented in Table 1, the following characteristics were found during interviews with the entrepreneurs in small medium contractors in Indonesia.

- Integrity to build clients' trust which is embodied as honest, having moral principles and keeping promises to clients

- Passion fot working for the project because they consider working in construction projects as a hobby.

- Survival spirit in order to deal with the unstable condition of construction industry in Indonesia. For example they are able to survive during the monetary crisis in 1998.

\section{Discussions}

After all characteristics of entrepreneurs in small medium contractors in Indonesia examined further, they are mainly linked to projects and clients. This finding is in accordance with the nature of contractors' business. In order to be successful in business, contractors face two main challenges, those are to win the competition to get the project and to deliver the project successfully [27]. These two challenges are mainly related to clients and projects.

In addition to manage projects, contractors also need to manage their business, however project and business have different characteristics. Business processes involve repetitive activities while projects usually involve temporary and unique activities [28]. 
Table 1. Specific characteristics of small medium contractors entrepreneurs

\begin{tabular}{|c|c|}
\hline $\begin{array}{c}\text { General } \\
\text { characteristics }\end{array}$ & $\begin{array}{c}\text { Characteristics of small medium contractor entrepreneurs } \\
\text { and their explanations and examples }\end{array}$ \\
\hline \multirow[t]{2}{*}{ Risk Taking } & $\begin{array}{l}\text { Risk taking in dealing with clients } \\
\text { Bold actions to make a deal with clients because of a risk that come from } \\
\text { clients, such as late payment, design change, unreasonable requests, etc. }\end{array}$ \\
\hline & $\begin{array}{l}\text { Risk taking to complete project on time, on budget and on quality } \\
\text { Bold actions to complete project on time, on budget and on quality } \\
\text { because they should be committed before the project begins. }\end{array}$ \\
\hline \multirow[t]{2}{*}{$\begin{array}{l}\text { Need for } \\
\text { Achievement }\end{array}$} & $\begin{array}{l}\text { Ambition to complete the projects quickly and flawlessly } \\
\text { This spirit supports client's satisfaction and trustworthy making them to be } \\
\text { a loyal client and then they will bring in a repeat order. }\end{array}$ \\
\hline & $\begin{array}{l}\text { Ambition to expand the scope of business } \\
\text { This ambition is a growth instinct that was implemented through several } \\
\text { activities such as: } \\
\text { - investment on new equipment in order to get more projects } \\
\text { - running business diversification such as property developer }\end{array}$ \\
\hline $\begin{array}{l}\text { Internal Locus of } \\
\text { Control }\end{array}$ & $\begin{array}{l}\text { Awareness that the success of business depending on hard work } \\
\text { The business sustainability is the result of hard work in order to complete } \\
\text { the projects properly and to satisfy clients' needs. }\end{array}$ \\
\hline \multirow[t]{2}{*}{ Self-confidence } & $\begin{array}{l}\text { Self-confidence to compete for projects } \\
\text { In some occasions, contractors must compete with bigger contractors } \\
\text { therefore self-confident is needed. }\end{array}$ \\
\hline & $\begin{array}{l}\text { Self-confidence to make a deal with clients } \\
\text { To be confident is needed in order to acquire equal position with the client } \\
\text { as service provider and user }\end{array}$ \\
\hline \multirow[t]{2}{*}{$\begin{array}{l}\text { Tolerance of } \\
\text { Ambiguity }\end{array}$} & $\begin{array}{l}\text { Tolerance to the projects under uncertain condition } \\
\text { During construction stage, contractor entrepreneurs face ambiguous } \\
\text { situation in technical, political, social and economic aspects, therefore they } \\
\text { must have high tolerance to this situasion and anticipate the way out to } \\
\text { solve the problems. }\end{array}$ \\
\hline & $\begin{array}{l}\text { Tolerance to the needs of clients } \\
\text { Clients who involve intensively to the construction process, sometimes } \\
\text { have unexpected needs, such as short project duration and design changes. } \\
\text { In order to deal with these needs, contractor entrepreneurs have to be } \\
\text { tolerant with ambiguous situations by devising appropriate strategies }\end{array}$ \\
\hline \multirow[t]{2}{*}{ Proactiveness } & $\begin{array}{l}\text { Proactive to get the projects } \\
\text { This proactive action is manifested into several activities such as } \\
\text { - proactively find information about new projects and then approaching } \\
\text { the owners. } \\
\text { - carrying-out marketing activities such as preparing web-site, sending } \\
\text { company profile to the potential clients }\end{array}$ \\
\hline & $\begin{array}{l}\text { Find opportunities in a new market } \\
\text { Contractor entrepreneurs should be responsive to the opportunities that } \\
\text { available in the market, for example when infrastructure projects are } \\
\text { booming, they expand the market from private to public clients }\end{array}$ \\
\hline \multirow{2}{*}{$\begin{array}{l}\text { Innovativeness } \\
\text { (Instead of } \\
\text { innovative, } \\
\text { creative was } \\
\text { found more } \\
\text { suitable) }\end{array}$} & $\begin{array}{l}\text { Meet client's demands and solve clients' problems creatively } \\
\text { Client's demands and problems are unpredictable, therefore contractors } \\
\text { entrepreneurs need to be creative to meet client's demands and to solve } \\
\text { client's problems }\end{array}$ \\
\hline & $\begin{array}{l}\text { Manage the business creatively and effectively } \\
\text { The contractor entrepreneurs need to consider the following strategies: } \\
\text { - managing projects' cash flow and resources allocation, } \\
\text { - implementing profit sharing system with project teams in order to } \\
\text { increase the loyalty and the performance of project teams. }\end{array}$ \\
\hline
\end{tabular}


Considering their different characteristics, instead of managing the projects, contractors also have a challenge to manage their business. Therefore the findings of this study also shows the characteristics of small medium contractor entrepreneurs that linked to how to develop their business, such as: proactive to expand the company, creative to meet client's demands and to solve clients' problems, creative to manage the business effectively.

Regarding the findings of this study that has been discussed above, the characteristics of small medium contractor entrepreneurs were directed to get projects, to serve clients and to manage business. Figure 1 shows a clear picture about the findings of this study.

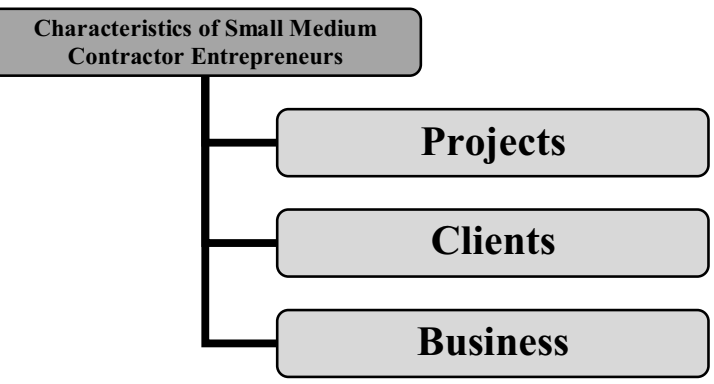

Fig. 1. The findings of this study

\section{Conclusions and Recommendations}

The literature review of the characteristics of entrepreneurs has found eight characteristics that distinguish entrepreneurs from peoples who do not have entrepreneurial tendencies. The eight characteristics are: risk taking, innovativeness, need for achievement, selfconfident, internal locus of control, tolerance of ambiguity, need for autonomy and proactiveness. After obtaining these characteristics, this study conducted research to investigate the characteristics of small medium contractor entrepreneurs.

Thirteen characteristics were identified by this study, these 13 characteristics can be classified into the characteristics that have been adopted in this study, except need of autonomy. In addition, this study also found another three characteristics such as: integrity, passion and survival instinct, therefore overall this study found 16 characteristics of small medium contractor entrepreneurs.

These findings were explored through the experiences of small medium contractors entrepreneurs in Indonesia, therefore they were influenced by the particular circumstances of each contractor's business environment in Indonesia. For this reason these characteristics need modifications before they can be adopted by contractors entrepreneurs in other countries.

During the study, several areas have been identified to be investigated further in the future. The potential research topics that can be studied further are listed below.

- To investigate the characteristics of entrepreneurs in a different country or in a different project based industry

- To develop a comprehensive questionnaire as a tool to assess characteristics of contractor entrepreneurs

- To assess the entrepreneurial characteristics of contractor entrepreneurs in Indonesia, or another country, by assessing a large number of contractors entrepreneurs based on the entrepreneurial characteristics found in this study. 


\section{Acknowledgement}

We thank the Ministry of Research, Technology and Higher Education of the Republic of Indonesia that has funded this study through the Scheme of Fundamental Research.

\section{References}

1. J. M. W. Wong, S. T. Ng, A. P. C. Chan, Habitat Int J, 34, 256 (2010)

2. G. M. Winch, Managing construction projects : An information processing approach (2010)

3. D. W. Halpin, R. W. Woodhead, Construction management (2011)

4. D. Dvir, A. Sadeh, A. Malach-Pines, PMJ, 37, 5, 36 (2006)

5. J. Schaufelberger, Construction business management (2009)

6. S. Yalcin, H. Kapu, JDE, 13, 2, 185 (2008)

7. A. S. Spencer, B. A. Kirchhoff, C. White, ISBJ., 26, 1, 9 (2008)

8. J. Wiklund, D. Shepherd, SMJ. 24, 13, 1307 (2003)

9. S. R. H. Brockhaus, AMJ., 23, 3, 509 (1980)

10. V. Luchsinger, D. Ray Bagby, SAM AMJ. 52, 3, 10 (1987)

11. R. F. Hebert, A. N. Link, SBE, 1, 1, 39 (1989)

12. P. Sharma, J. J. Chrisman, ET\&P, 23, 3, 11 (1999)

13. E. P. Lazear, JOLE, 23, 4, 649 (2005)

14. B. Thompson, Entrepreneurs : Talent, temperament, technique (2004)

15. R. A. Baron, SEJ, 1, 1-2, 167 (2007)

16. W. B. Gartner, AJOSB, 12, 4, 11 (1988)

17. P. Burns, Corporate entrepreneurship: Building an entrepreneurial organisation (2005)

18. H. C. Koh, JMP, 11, 3, 12 (1996)

19. K. Tajeddini, S. L. Mueller, JIE, 7, 1, 1 (2009)

20. S. Sidek, F. A. Zainol, IBM, 2, 1, 170 (2011)

21. M. Frese, FTE, 5, 6, 437 (2009)

22. D.C. McClelland, The achieving society (1961)

23. M. Van Gelderen, P. Jansen, S. Jonges, SCALES-paper N200315 (2003)

24. G. T. Lumpkin, G. G. Dess, AMR, 21, 1, 135 (1996)

25. C. Quinlan, Business research methods (2011)

26. V. Braun, V. Clarke, QRP, 3, 2, 77 (2006)

27. P. Volpe, P. J. Volpe, Construction business management (Wiley, Canada, 1991)

28. D. M. Gann, A. J. Salter, RP, 29, 955 (2000) 